\title{
Examining Associations Between Physical Activity and Academic Performance in a Large Sample of Ontario Students: The Role of Inattention and Hyperactivity
}

\author{
Michelle Ogrodnik, Jillian Halladay, Barbara Fenesi, Jennifer Heisz, and Katholiki Georgiades
}

\begin{abstract}
Background: Participation in physical activity (PA) is a modifiable factor that contributes to academic success, yet the optimal dose (ie, frequency) and mechanisms underlying the effect require further exploration. Methods: Using data from 19,886 elementary and 11,238 secondary school students across Ontario, Canada, this study examined associations between PA participation frequency, academic achievement, and inattention and hyperactivity. Results: Among elementary students, there was a positive association between PA frequency and academic achievement. Participating in 1 to 2 days per week of PA related to higher academic achievement compared with no days, whereas 7 days per week had the largest associations. For secondary students, a minimum of 3 to 4 days per week was associated with higher academic achievement with no significant benefit of additional days. Indirect effects of inattention and hyperactivity were found for both groups, suggesting that the benefits of PA on academic achievement may be partly explained by reductions in inattention and hyperactivity, especially for secondary school students. Conclusion: Students may experience academic benefits from PA even if they are not meeting the guidelines of exercising daily. These benefits may occur, in part, through reductions in inattention and hyperactivity. Further work is needed to determine the temporality and mechanism of these associations.
\end{abstract}

Keywords: elementary students, secondary students, exercise, attention

Schools face increasing societal pressure to produce academically successful students. In attempts to meet these demands, teachers and school boards often increase time for scholastic activities, including mathematics, science, and reading, at the cost of other subjects and extracurriculars. ${ }^{1,2}$ If academic achievement was merely a function of time-on-task, this approach would make sense. However, there is much more involved. One important and often overlooked factor associated with improved academic achievement is participation in physical activity (PA). ${ }^{3,4}$ Previous work has shown that children who are more physically active and physically fit perform better academically than their less physically active and fit peers. ${ }^{5-11}$ Interventions that increase PA in the daily curriculum have also been shown to improve academic achievement. ${ }^{12-14}$ However, it remains unclear exactly how PA participation improves academic achievement and whether a certain frequency needs to be performed for students to experience academic benefits.

Understanding how PA improves academic achievement is critical for optimizing the implementation of PA interventions for classrooms and students. A key set of cognitive abilities thought to be impacted by PA and posited to explain improvements in academic achievement are executive functions - a set of cognitive processes that govern goal-oriented behavior such as inhibitory control, cognitive flexibility, set shifting, and working memory. ${ }^{14-18}$ Both an acute bout of PA and regular PA participation have been shown to improve executive functions. ${ }^{19,20}$ Though both acute and regular participation have shown benefits, identifying whether there is a

Ogrodnik and Heisz are with the Department of Kinesiology, McMaster University, Hamilton, ON, Canada. Halladay and Georgiades are with the Department of Health Research, Evidence, and Impact, McMaster University, Hamilton, ON, Canada. Fenesi is with the Department of Education, Western University, London, ON, Canada. Ogrodnik (ogrodnm@mcmaster.ca) is corresponding author. necessary frequency of PA to benefit academic achievement remains unclear. Thus, the first goal of this study was to quantify the association between PA frequency and academic achievement. For children and adolescence (between the ages of 5 and 17 y old), the PA guidelines typically recommend at least 60 minutes of moderate to vigorous PA per day for overall physical and mental health. ${ }^{21}$ However, it is unclear whether similar guidelines apply for other important developmental outcomes, such as academic achievement and cognition, more broadly.

Differences in socioeconomic position, gender, and age are important to consider when quantifying the association between PA participation and academic achievement. Children and adolescents of lower socioeconomic status experience inequalities in access to resources, which can result in fewer opportunities to engage in $\mathrm{PA}^{22}$ and poorer academic performance. ${ }^{23}$ The impact of gender socialization on academic achievement ${ }^{24}$ and PA participation ${ }^{25}$ is also important to consider, given some evidence that finds girls can have poorer performance in certain subjects (eg, math) and participate in less PA than boys. Some evidence suggests that although age is positively associated with academic achievement, ${ }^{24}$ there is strong evidence for a negative association with PA participation; for example, the transition into adolescence is marked by a significant reduction in PA participation. ${ }^{26}$ Thus, any analyses of PA and academic achievement should take these sociodemographic characteristics into consideration.

Another key finding within the literature is that deficits in focused and sustained attention can be improved through PA participation (see de Sousa et $\mathrm{al}^{27}$ and de Greeff et $\mathrm{al}^{28}$ for recent meta-analyses). ${ }^{14}$ There are numerous mechanisms proposed to explain the association between PA and cognition (which encompasses focused attention), including physiological mechanisms and learning/developmental mechanisms. ${ }^{3}$ The physiological mechanisms, such as modified arousal levels, increased cerebral blood 
flow, changes in brain neurotransmitters, and structural changes to the nervous system, are based on physical changes in the body as a result of PA. The learning/developmental mechanisms suggest that PA provides learning experiences that foster cognitive development, including improved attentional focus. To our knowledge, no prior studies have examined the role of inattention and hyperactivity in the association between PA and academic achievement in a large representative sample of students. Thus, another objective of this study was to examine the extent to which inattention and hyperactivity may account for associations between PA and academic achievement.

Furthermore, executive functions have a relatively slow developmental trajectory from childhood into late adolescence, with several periods of rapid growth identified during the first 2 years of life, at the beginning of adolescence with the onset of puberty, and at the end of adolescence during the transition into adulthood. ${ }^{29,30}$ If benefits to executive functions underlie the association between PA and academic achievement, then associations may differ across developmental periods. As such, we aimed to examine whether differences exist between elementary and secondary school students when considering the role of PA on inattention and hyperactivity and academic achievement. Though previous evidence suggests that elementary and middle school students benefit more from PA on outcomes of cognitive function than secondary school students, ${ }^{3}$ when considering the effect of inattention and hyperactivity, it remains unclear whether there are differences between elementary and secondary school students.

\section{Objectives}

Using a large representative sample of elementary and secondary school students across Ontario, Canada, the current study examined associations between the frequency of PA participation (number of days completing $60 \mathrm{~min} / \mathrm{d}$ of moderate to vigorous PA), academic achievement, and the role of inattention and hyperactivity within this relationship. The objectives of the current study were to examine: (1) the strength of association between frequency of PA and academic achievement, (2) the degree to which inattention and hyperactivity may account for the association between PA and academic achievement, and (3) school-level differences between elementary and secondary school students. We hypothesized that more days spent being physically active would be positively associated with higher academic achievement in both elementary school and secondary school students and that inattention and hyperactivity would significantly account for this association.

\section{Methods}

\section{Sample Data}

Data for analyses came from the School Mental Health Surveys (SMHS), a cross-sectional survey of 248 schools in Ontario (180 elementary schools and 68 secondary schools) during the 20142015 academic year. The SMHS was designed to examine associations between school and classroom contexts and student mental health and psychosocial outcomes. The selection of schools was based on the sampling design of a companion study, the 2014 Ontario Child Health Study. ${ }^{31}$ Within selected schools, anonymous surveys were administered to all students enrolled in grade 6 to 8 classrooms in elementary schools and a random sample of 3 classrooms per grade in secondary schools. In total, survey data was collected from 19,886 elementary school students (response rate $=$
$62.3 \%$ ) and 11,238 secondary school students (response rate= $60.5 \%)$.

\section{Variables}

Dependent Variable. Achievement: Items capturing student academic achievement were taken from the Ontario Child Health Study. ${ }^{32}$ The students were asked, "Based on your report card and school work, how are you doing in the following subjects: 1) English/ Language (reading, writing, and oral communication), 2) Mathematics, and 3) Overall?" Item 3 was modified from "On average across your subjects" to "How are you doing overall." Response options include A (80-90), B (70-79), C (60-69), and D or lower $(<60)$. Items were reverse coded wherein higher scores reflected better grades (coded 1 to 4). An additional response option "Do not take this subject" was included and coded as missing. A composite variable of overall academic achievement was calculated by taking the mean of these 3 items wherein a higher score reflected better overall academic achievement. Factor analysis revealed strong item loadings on a single factor $(-0.80)$ that accounted for over $70 \%$ of the variation among elementary and secondary school students with good internal consistency ( $a=0.98$ elementary and 0.77 secondary).

Predictor Variables. Physical activity: The students were asked, "Over the past seven days, on how many days did you engage in PA for at least 60 minutes, that increased your heart rate and made you get out of breath?" Response options included: " 0 " = no days, " 1 " = 1 to 2 days, " 2 " = 3 to 4 days, " 3 " = 5 to 6 days, or " 4 " = every day, with no days serving as the reference category.

Inattention and hyperactivity: Inattention and hyperactivity were measured using items from the Attention Deficit Hyperactivity Disorder subscale of the Ontario Child Health Study: Emotional Behavioral Scales, which was comprised of 4 items. ${ }^{33}$ The students were asked, (1) "I have trouble concentrating or paying attention," (2) "I am easily distracted, have difficulty sticking to any activity," (3) "I have trouble sitting still," and (4) "I fail to finish things I start." Items were scored on a Likert scale ranging from " 1 " never or not true to " 3 " often or very true. Items were summed with a minimum score of 4 and maximum score of 12 wherein higher scores reflected greater inattention and hyperactivity. This scale yielded acceptable internal consistency in elementary school $(a=0.75)$ and secondary school students $(a=0.76)$.

Covariates. Gender: The students were asked to self-identify as " 0 " male or " 1 " female.

Age: The students were asked to indicate their age based on response options ranging from 9 to 22 years of age.

Family assets: Items were adapted from the Health Behavior in School Aged Children Survey. ${ }^{34}$ Students self-reported their family's assets, including how many vehicles, computers, cell phones, or electronic tablets their family owned. A standardized factor score $(z$ score) was derived using principal component analysis of the 4 items wherein higher scores indicated greater assets. A single factor emerged with an eigenvalue $>1$ and accounted for $45.3 \%$ of the variance in elementary school students and $46.3 \%$ in secondary school students.

\section{Statistical Analysis}

Missing data was present for $9.2 \%$ of elementary school students $(1766 / 19,130)$ and $5.3 \%$ of secondary school students $(640 / 11,994)$. Among elementary school students with missing information, the majority (62\%) were missing only one item. The 
absolute percentage of missing data ranged from $0.38 \%$ (for age) to $6.12 \%$ (for family assets). Among secondary school students with missing information, $74 \%$ were missing only one item. Absolute missing responses ranged from $0.38 \%$ (for age) to $3.23 \%$ (for family assets). A series of multilevel univariate logistic regressions were performed to predict missingness wherein missingness was coded as " 1 " and complete data was coded as " 0 ." Missingness among both elementary and secondary school students was related to lower academic achievement, lower family assets, higher inattention and hyperactivity, and identifying as male. Missing data were accounted for through multilevel multiple imputation using fully conditional speciation in Blimp 2.0. ${ }^{35,36}$ Imputations were run separately for elementary and secondary school samples using all variables present in the analytical models. A total of 20 imputations (>98\% efficiency across all variables) were generated with a burnin phase of 2000 and thinning of 500 using the Gibbs sampler algorithm. ${ }^{37,38}$

To address the study objectives, a series of 3-level linear regression models were conducted (school, class, and student) using generalized linear regression models while accounting for random intercepts at the classroom and school levels. Imputed data (from Blimp) were imported to SAS (enterprise 7.1, SAS Institute Inc., Cary, NC) where imputed values were readjusted to retain a viable minimum and maximum estimate for continuous variables. Models were estimated using SAS ${ }^{\circledR}$ Enterprise (guide 7.1, PROC GLIMMIX, METHOD=RSPL) with all independent variables and covariates estimated as fixed effects. All models were adjusted for age, gender, and family assets. Regression coefficients were estimated by imputation, pooling estimates, and standard errors for final results using Rubin rules. ${ }^{39}$

To examine direct and indirect effects of PA and inattention and hyperactivity, the component approach (also known as joint significance) and index approach (product of coefficients method) were used. ${ }^{40}$ Of note, the model used was a 1-1-1 multilevel mediation wherein the primary independent variable $(X, \mathrm{PA})$, the hypothesized mediator $(M$, inattention and hyperactivity), and the dependent variable ( $Y$, academic achievement) were all level 1 (student) variables. Using common language to mediation analysis, the word path was used to describe specific beta coefficients depicting associations between $X, M$, and $Y$ within different regression models. First, a series of multilevel models were conducted, including regressing: model (1) academic achievement on inattention and hyperactivity ( $m$ path), model (2) academic achievement on PA ( $c$ path), model (3) inattention and hyperactivity on PA ( $a$ path), and model (4) academic achievement on PA ( $c^{\prime}$ path) and inattention and hyperactivity ( $b$ path) (ie, the fully adjusted model). Of note, both $c^{\prime}$ and $b$ path were estimated using the same regression equation; however, they reflected different beta coefficients. According to the component approach, the $a$ path and $b$ path needed to be significant to provide evidence for an indirect effect (note: contemporary research suggests $c$ and $c^{\prime}$ do not need to be significant to support indirect effects). ${ }^{38,39}$ Figure 1 provides a structural depiction of the component approach. Equality tests were done to confirm accurate estimation for joint significance tests (Supplementary Tables 1 and 2 [available online]). The following represent the main model equations:

Model 1 (includes $m$ path): $Y(\text { achieve })_{\mathrm{ijk}}=B_{0 \mathrm{ijk}}+B\left(C_{\mathrm{fem}}\right)_{\mathrm{ij}}+$ $B\left(C_{\mathrm{age}}\right)_{\mathrm{ijk}}+B\left(C_{\mathrm{SES}}\right)_{\mathrm{ijk}}+B\left(M_{\text {inattention/hyperactivity }}\right)_{\mathrm{ijk}}+v_{0 \mathrm{k}}+$ $u_{0 \mathrm{jk}}+e_{0 \mathrm{ijk}}$

Model 2 (includes $c$ path): $Y(\text { achieve })_{\mathrm{ijk}}=B_{0 \mathrm{ijk}}+B\left(C_{\mathrm{fem}}\right)_{\mathrm{ij}}+$ $B\left(C_{\mathrm{age}}\right)_{\mathrm{ijk}}+B\left(C_{\mathrm{SES}}\right)_{\mathrm{ijk}}+B\left(X_{1-2 \text { days }}\right)_{\mathrm{ijk}}+B\left(X_{3-4 \text { days }}\right)_{\mathrm{ijk}}+$ $\left.B_{\left(X_{5-6 \text { days }}\right.}\right)_{\mathrm{ijk}}+B\left(X_{\text {everyday }}\right)_{\mathrm{ijk}}+v_{0 \mathrm{k}}+u_{0 \mathrm{jk}}+e_{0 \mathrm{ijk}}$

Model 3 (includes $a$ path): $Y(\text { inattention and hyperactivity })_{\mathrm{ijk}}=$ $B_{0 \mathrm{ijk}}+B\left(C_{\mathrm{fem}}\right)_{\mathrm{ij}}+B\left(C_{\mathrm{age}}\right)_{\mathrm{ijk}}+B\left(C_{\mathrm{SES}}\right)_{\mathrm{ijk}}+B\left(X_{1-2 \text { days }}\right)_{\mathrm{ijk}}+$ $B\left(X_{3-4 \text { days }}\right)_{\mathrm{ijk}}+B\left(X_{5-6 \text { days }}\right)_{\mathrm{ijk}}+B\left(X_{\text {everyday }}\right)_{\mathrm{ijk}}+v_{0 \mathrm{k}}+u_{0 \mathrm{jk}}+e_{0 \mathrm{ijk}}$ Model 4 (includes $c^{\prime}$ and $b$ path): $Y(\text { achieve })_{\mathrm{ijk}}=B_{0 \mathrm{ijk}}+$ $B\left(C_{\mathrm{fem}}\right)_{\mathrm{ij}}+B\left(C_{\mathrm{age}}\right)_{\mathrm{ijk}}+B\left(C_{\mathrm{SES}}\right)_{\mathrm{ijk}}+B\left(X_{1-2 \text { days }}\right)_{\mathrm{ijk}}+B\left(X_{3-4 \text { days }}\right)_{\mathrm{ijk}}+$ $B\left(X_{5-6 \text { days }}\right)_{\mathrm{ijk}}+B\left(X_{\text {everyday }}\right)_{\mathrm{ijk}}+B\left(M_{\text {inattention and hyperactivity }}\right)_{\mathrm{ijk}}+$ $v_{0 \mathrm{k}}+u_{0 \mathrm{jk}}+e_{0 \mathrm{ijk}}$

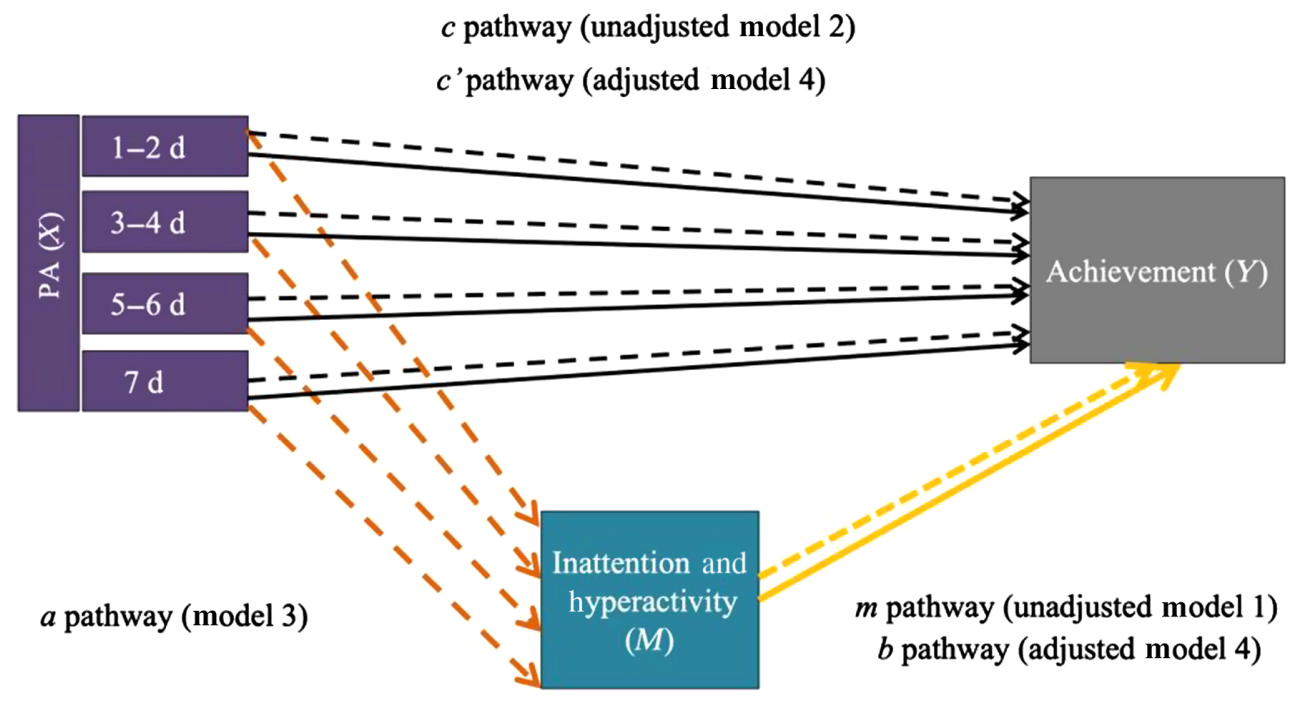

$\longrightarrow$ "unadjusted" (adjusted for gender, age, and family assets)
$\longrightarrow$ "adjusted" (fully adjusted model with all variables)

Figure 1 - Structural depiction of the component approach. PA indicates physical activity. 
where $C=$ covariate, $X=$ main independent variables (PA), $M=$ mediator/indirect effect (inattention and hyperactivity), ijk $=$ student level or level $1, \mathrm{jk}=$ class level or level $2, \mathrm{k}=$ school level or level 3. The variable $B_{0 \mathrm{ijk}}$ denotes random intercepts, where the residual variance is partitioned into school $\left(\mathrm{v}_{0 \mathrm{k}}\right)$, class $\left(\mathrm{u}_{0 \mathrm{ik}}\right)$, and student $\left(\mathrm{e}_{0 \mathrm{ijk}}\right)$; fixed effects at student level of measurement $\left(B_{\mathrm{ijk}}\right)$ with a student level outcome $\left(y_{\mathrm{ijk}}\right)$.

Next, the index approach was used to provide a single mediation effect estimate for each dummy coded PA variable. The product of coefficients method was used by taking the product of $a$ and $b$ (ie, $a b$ ) and calculating 95\% confidence intervals (CIs) using the Monte Carlo method for assessing mediation. ${ }^{40,41}$ This approach uses $a, b$, and their asymptotic variances (note: covariance $=0$ ). This approach is appropriate for the multilevel imputed data, as the series of regressions were done via multilevel modeling across imputed data sets, where $a$ and $b$ were included as fixed effects only. ${ }^{42,43}$ A $P$ value of $<.05$ was used as evidence of significant indirect effects. Model fit was also compared using -2 log-likelihood (-2LL) ratio tests whereby the change in $-2 \mathrm{LL}$ alongside the degrees of freedom is compared with the $X^{2}$ distribution with $P<.05$ denoting improvements in model fit.

\section{Ethics}

All study procedures, including consent and confidentiality requirements, were approved by the Hamilton Integrated Research Ethics Board at McMaster University and the Research Ethics Committees of the School Boards involved in the study. The participating school boards approved the SMHS and designated which type of consent process was to be implemented: (1) an information form sent home with students that was only signed and returned if parents did not want their child to complete the survey, (2) an information form sent home with students that had to be signed by parents and returned in order for the child to receive a survey, or (3) both a parent and the child had to sign the form indicating permission to complete the survey. In all cases, only data from participants who consented was analyzed.

\section{Results}

Table 1 presents sample characteristics separately for elementary and secondary school students. Males and females were nearly evenly distributed across elementary and secondary schools (52\% females in both school levels). In elementary schools, about $41 \%$ of students met the PA guidelines compared with only $28 \%$ of secondary school students (Table 1). All subsequent regression analyses were adjusted for age, gender, and family assets. Adjusted beta coefficients and 95\% CIs for the associations between PA, inattention and hyperactivity, and academic achievement among elementary and secondary school students are presented in Tables 2 and 3 , respectively.

\section{Elementary School Students}

Table 2 presents models 1 to 4 among elementary school students. The dependent variable for models 1, 2, and 4 was academic achievement, whereas the dependent variable in model 3 was inattention and hyperactivity. Being female and having greater family assets were consistently related to higher academic achievement and lower inattention and hyperactivity across all models. Age was positively related to achievement and inattention and
Table 1 Descriptive Statistics and Sample Characteristics by School Level

\begin{tabular}{|c|c|c|}
\hline & $\begin{array}{l}\text { Elementary } \\
(n=19,130)\end{array}$ & $\begin{array}{l}\text { Secondary } \\
(n=11,994)\end{array}$ \\
\hline Variables & $\begin{array}{l}\text { Imputed \% or } \\
\text { mean (SD) }\end{array}$ & $\begin{array}{l}\text { Imputed \% or } \\
\text { mean (SD) }\end{array}$ \\
\hline \multicolumn{3}{|l|}{ Covariates } \\
\hline Female gender, $\%$ & $52.17 \%$ & $51.44 \%$ \\
\hline Age, mean (SD) & $12.2(1.07)$ & $15.56(1.47)$ \\
\hline Family assets, mean (SD) & $-0.05(1.03)$ & $0.07(1.01)$ \\
\hline \multicolumn{3}{|l|}{$\begin{array}{l}\text { Main predictor: PA partici- } \\
\text { pation frequencies }\end{array}$} \\
\hline No days, $\%$ & $6.55 \%$ & $14.83 \%$ \\
\hline $1-2 \mathrm{~d}, \%$ & $12.64 \%$ & $18.10 \%$ \\
\hline $3-4 \mathrm{~d}, \%$ & $18.23 \%$ & $20.73 \%$ \\
\hline $5-6 \mathrm{~d}, \%$ & $21.78 \%$ & $17.83 \%$ \\
\hline $7 \mathrm{~d}, \%$ & $40.80 \%$ & $28.51 \%$ \\
\hline \multicolumn{3}{|l|}{$\begin{array}{l}\text { Hypothesized indirect } \\
\text { variable }\end{array}$} \\
\hline $\begin{array}{l}\text { Inattention and hyperac- } \\
\text { tivity, mean (SD) }\end{array}$ & $6.51(2.06)$ & $7.08(2.10)$ \\
\hline \multicolumn{3}{|l|}{ Main outcome } \\
\hline $\begin{array}{l}\text { Overall achievement, } \\
\text { mean (SD) }\end{array}$ & $3.30(0.64)$ & $3.24(0.75)$ \\
\hline
\end{tabular}

hyperactivity. In model 1 , as expected, inattention and hyperactivity were associated with lower levels of academic achievement $(B=-0.11 ; 95 \% \mathrm{CI},-0.11$ to -0.10$)$. In model 2 , point estimates associated with frequency of engaging in PA appeared to reflect a dose-response relationship between the number of days of PA and academic achievement wherein more days of PA was related to higher academic achievement. Compared with " 0 " days, even endorsing 1 to 2 days of PA ( $B=0.08 ; 95 \% \mathrm{CI}, 0.04$ to 0.13$)$ was positively related to academic achievement, with each additional increase in the frequency of PA resulting in a significant increase in academic achievement. ${ }^{\mathrm{I}}$ Thus, the largest association was between 7 days of PA and academic achievement $(B=0.27$; $95 \% \mathrm{CI}, 0.23$ to 0.30 ). The frequency of PA was also significantly and inversely related to inattention and hyperactivity with more days of PA yielding larger effect sizes (point estimates from -0.16 to -0.85 ; see model 3 ). In model 4 , after adjusting for inattention and hyperactivity, the frequency of PA remained positively related to academic achievement in a dose-response fashion, although the magnitudes of these effects were slightly attenuated (point estimates ranged from 0.07 to 0.18). Higher frequencies of PA appeared to have larger attenuation (eg, the effect size of 1 to 2 days was reduced by $12.4 \%$, whereas every day was reduced by $33.4 \%$ ). Inattention and hyperactivity remained significantly and inversely related to academic achievement. See Supplementary Figure 1 (available online) for a path diagram including model estimates. Thus, according to the component approach, there was evidence of an indirect effect given that the $a$ and $b$ paths were significant. Furthermore, evidence of significant indirect effects at all PA frequencies were found through the index approach (Table 4 for products and Monte Carlo method for assessing mediation method 95\% CI). Finally, model fit significantly improved in the fully adjusted models based on the difference in pseudo-2LL, and in fully adjusted models, the variance inflation factor (VIF) did not 

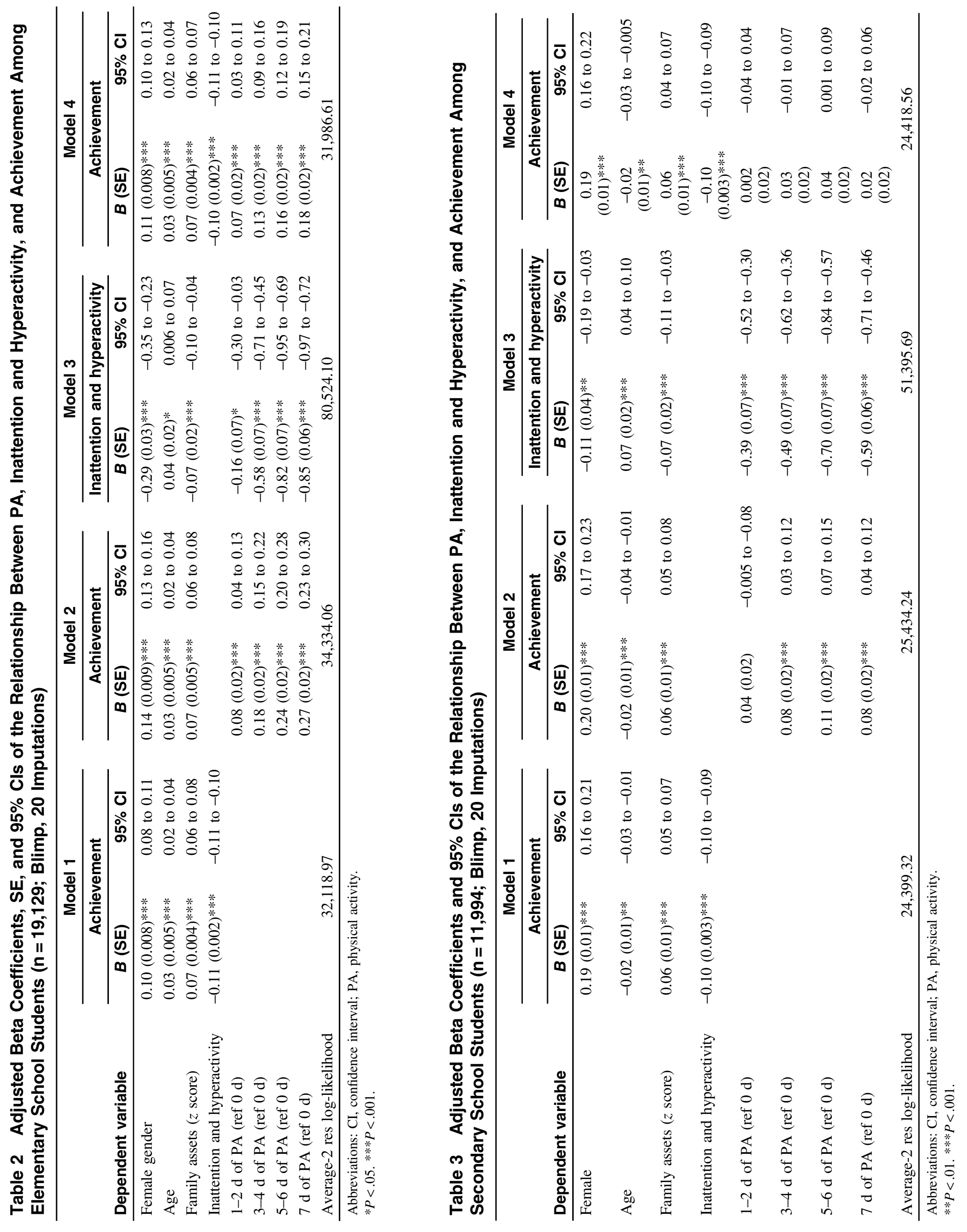
Table 4 Indirect Effects Calculated Through the Index Approach With 95\% Cls Calculated Using the Monte Carlo Method for Assessing Mediation Method Among Elementary Students

\begin{tabular}{lcc}
\hline PA Frequency & $\boldsymbol{a} \times \boldsymbol{b}$ & $\mathbf{9 5 \%} \mathbf{C l}$ \\
\hline 1-2 d of PA & $0.02^{*}$ & 0.003 to 0.03 \\
3-4 d of PA & $0.06^{*}$ & 0.05 to 0.07 \\
5-6 d of PA & $0.08^{*}$ & 0.07 to 0.10 \\
7 d of PA & $0.09^{*}$ & 0.07 to 0.10
\end{tabular}

Abbreviations: CI, confidence interval; PA, physical activity.

$*$ All less than $P<.05$.

exceed 4, which is below the accepted cutoff for multicollinearity of VIF $>10$ (see Supplementary Table 3 [available online] for specific VIFs). Overall, among elementary school students, more days of PA was related to higher academic achievement, and there was evidence that this may be partly explained by associated reductions in inattention and hyperactivity.

\section{Secondary School Students}

Table 3 presents models 1 to 4 among secondary school students. The dependent variable for models 1,2 , and 4 was academic achievement, whereas the dependent variable in model 3 was inattention and hyperactivity. Associations for gender and family assets were consistent with findings among elementary school students, whereas age had distinct associations. Younger aged secondary school students had lower academic achievement than older students, whereas older students had higher inattention and hyperactivity than younger students. Similar to elementary school students, in the partially adjusted models (models 1 and 2), inattention and hyperactivity was associated with lower levels of academic achievement ( $B=-0.10 ; 95 \% \mathrm{CI},-0.10$ to -0.09$)$, whereas engaging in PA was positively related to academic achievement. When testing the relationship between PA and inattention and hyperactivity (model 3), they were found to be inversely related as seen among elementary school students. When looking at the magnitude of associations between PA and academic achievement, point estimates were similar for 3 to 4 days of PA $(B=0.08), 5$ to 6 days $(B=0.11)$, and 7 days $(B=0.08)$ when compared with 0 days and not significantly different from one

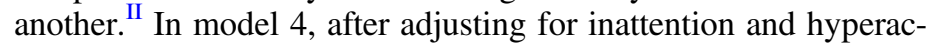
tivity, PA was no longer independently related to academic achievement (all $P \mathrm{~s}>.05$ ) and inattention and hyperactivity remained significantly inversely related to academic achievement in the fully adjusted model (see Supplementary Figure 2 [available online]). According to the component approach, there was evidence of an indirect effect given that the $a$ and $b$ paths were significant. There was also evidence of significant indirect effects for all frequencies of PA found through the index approach among secondary school students (see Table 5 for products and Monte Carlo method for assessing mediation method 95\% CI). Finally, model fit significantly improved in the fully adjusted models based on the difference in pseudo -2LL, and in fully adjusted models, VIF did not exceed 2.2, indicating an absence of multicollinearity. Overall, among secondary school students, PA demonstrated indirect effects on academic achievement through associated reductions in inattention and hyperactivity.
Table 5 Indirect Effects Calculated Through the Index Approach With 95\% Cls Calculated Using the Monte Carlo Method for Assessing Mediation Method Among Secondary Students

\begin{tabular}{llc}
\hline PA Frequency & $\mathbf{a} \times \boldsymbol{b}$ & $\mathbf{9 5 \%} \mathbf{C l}$ \\
\hline 1-2 d of PA & $0.04^{*}$ & 0.03 to 0.05 \\
3-4 d of PA & $0.05^{*}$ & 0.03 to 0.06 \\
5-6 d of PA & $0.07^{*}$ & 0.06 to 0.08 \\
7 d of PA & $0.06^{*}$ & 0.04 to 0.08 \\
\hline
\end{tabular}

Abbreviations: CI, confidence interval; PA, physical activity.

*All less than $P<.05$.

\section{Comparing Secondary and Elementary School Students}

When the sample for analyses combined elementary and secondary school students (Supplementary Table 4 [available online]), associations between PA and academic achievement varied across elementary school students. Specifically, the positive associations between PA and academic achievement were attenuated among secondary school students in comparison to elementary school students. Prior to controlling for inattention and hyperactivity, all PA variables except 1 to 2 days were significantly smaller in magnitude among secondary school students compared with elementary school students following a dose-response pattern $\left(B_{34 \text { day- }}\right.$ sXsec $-0.11 ; B 56$ daysXsec $\left.-0.13 ; B_{7 \text { daysXsec }}-0.19\right)$. After controlling for inattention and hyperactivity, interactions between school level and PA remained significant for all interaction frequencies $\left(B_{12 \text { daysXsec }}\right.$ $\left.-0.06 ; B_{34 \text { daysXsec }}-0.10 ; B_{56 \text { daysXsec }}-0.12 ; B_{7 \text { daysXsec }}-0.17\right)$. Therefore, the association between academic achievement and PA frequency was significantly larger in magnitude for elementary school students in comparison to secondary school students. Of note with respect to VIF, the school level was not collinear with age as it reached 2.8, which is below the accepted cutoff.

\section{Discussion}

Using representative data from 19,886 elementary school students and 11,238 secondary school students in Ontario, we examined the extent to which PA participation frequency and inattention and hyperactivity related to academic achievement. Our findings suggest that higher PA participation was associated with higher academic achievement for both elementary and secondary school students, though the association between PA and academic achievement was significantly larger for elementary school students than for secondary school students. Moreover, the association with PA frequency differed across school levels as did the indirect effect of inattention and hyperactivity. For elementary school students, 1 to 2 days of PA was associated with improved academic achievement and each additional day of activity conferred greater benefits. Inattention and hyperactivity accounted for some, but not all, of this association. In contrast, for secondary school students, 3 to 4 days per week of PA was associated with improved academic achievement in comparison with no days, and there was no added benefit of additional days of activity. Here, inattention and hyperactivity fully accounted for the association between PA and academic achievement.

In line with previous research, our work highlights salient differences between elementary and secondary school students regarding the association between PA and academic achievement. 
In our sample, elementary school students conferred more academic benefit from PA than secondary school students. Previous researchers have suggested that movement helps stimulate cognitive development and that this is of particular importance for younger children. $3,44,45$ Previous research has also hypothesized that younger children may see greater academic benefits from more PA participation due to the unique social anxiety experienced by that age group. ${ }^{3,46}$ They argue that younger children (ie, children in grades 6-8) who are going through the first signs of physical changes associated with puberty begin to place more value on the opinions of peers and experience changes in self-esteem. Therefore, PA, in part, may have a greater impact on academic achievement in younger age groups because of the added benefit of decreasing anxiety or increasing self-esteem. However, this is only a hypothesis; further work is required to better understand the mechanism driving these differences.

Another important finding of this study was the evidence for indirect effects of lower inattention and hyperactivity on the association between PA and academic achievement in both elementary and secondary school students. Consistent with recent meta-analyses, ${ }^{23,24}$ our research helps delineate the benefits of PA for improving sustained attention, but also points to important differences in how much inattention and hyperactivity may account for the association. The effect of PA on inattention and hyperactivity fully accounted for improved academic achievement in secondary school students but not in elementary school students, suggesting that PA may confer alternative benefits over and above reducing inattention and hyperactivity for elementary school students. Although the current data set cannot speak to the direction of this effect, one hypothesis could be that sustained attention may be more critical for learning in secondary school; secondary school requires its students to concentrate for longer durations compared with learning in elementary school, which is punctuated with short and frequent breaks. More research is needed to disentangle what underlies the difference between school levels with respect to the role of attention.

A key contribution of this research is that our results serve as an important foundation for future studies to investigate frequency. Using more objective measurements of PA, researchers in this field should consider creating guidelines around the minimum necessary frequency of PA needed for enhanced academic achievement. Both the current PA guidelines in Canada ${ }^{21}$ and the guidelines from the World Health Organization ${ }^{47}$ recommend at least 60 minutes of moderate to vigorous PA for children 7 days per week to promote health and well-being. In our data set, only $41 \%$ of elementary school students and $28 \%$ of secondary school students were meeting those guidelines. Despite low adherence to the guidelines, when considering benefits to academic achievement, our results suggest that increasing the frequency of PA may be particularly important in elementary school students in comparison with secondary school students. Though we are unable to comment on exactly how many minutes students they were engaging in PA on each of their active days, when compared with no days, elementary school students benefitted from increasing amounts of PA in a dose-response pattern (with the greatest effects of $7 \mathrm{~d}$ a week). Secondary school students showed no additional academic benefit over and above 3 to 4 days spent physically active. However, it is important to note that our work suggests even 1 to 2 days per week can still benefit elementary school students; though the effect was small, we observed that those who reported participating in just 1 to 2 days per week of PA had higher academic achievement than those who reported participating in no days of PA. Compared with those participating in no days of PA, secondary school students participating 3 to 4 days a week saw significant academic benefits. Given that a limited number of students were actually meeting the guidelines in our sample, coupled with a 'lack of time' being one of the most commonly cited barriers to $\mathrm{PA},{ }^{48}$ these results are comforting as they show students can still experience academic benefits even if they do not always meet the target guidelines.

Exploring associations between PA, inattention and hyperactivity, and academic achievement has important implications for the use of PA as an intervention in the classroom. Teachers and school boards face pressure to ensure the academic success of their students, which often translates to greater time spent on scholastic tasks like reading and science at the cost of extracurriculars, including time for PA. ${ }^{2}$ However, research has shown that including PA breaks in classrooms can promote on-task attention and academic achievement. ${ }^{49-51} \mathrm{~A}$ more recent focus has turned to incorporating PA into teaching, by including cognitively demanding components in conjunction with the PA. ${ }^{16,52}$ As described in a recent systematic review and meta-analysis by Bedard et al, ${ }^{53}$ an example of this could include "a mathematics class [that] might have students perform jumping jacks or hop to indicate their answer to a question posed by a teacher." In the review, Bedard et $\mathrm{al}^{53}$ found a small positive effect of including cognitively engaging PA into lessons when compared with traditional didactic teaching. Coupling evidence for cognitively engaging PA with our results about frequency, future work may begin to construct guidelines for the use of PA to benefit academic achievement.

\section{Limitations and Implications for Future Research}

TThis research makes important contributions to our understanding of PA and academics using a large representative sample of elementary school and secondary school students across Ontario. The analysis was adjusted for potential confounders, including sociodemographic characteristics of students and the clustered nature of the data (individual, classroom, and school clustering). However, this work is not without limitations. First, although the estimations of indirect effects are still beneficial and appropriate with the cross-sectional data used, ${ }^{39}$ it is important to interpret the results as associations and indirect effects rather than mediation per se given the cross-sectional nature of the data. However, the indirect results alongside theoretical understandings of the relationship between PA and attention provide support for further exploration into the temporal mechanisms at play. Second, the data from this survey was collected via self-report. Although this is not uncommon for large epidemiological survey research assessing PA or academic achievement, future research should use more objective measures, including accelerometers for PA or report card data to assess academic achievement. In addition, the survey items used to measure PA did not include a measure of fitness or activity intensity. Therefore, we could only speak to the frequency of PA as reported by students themselves. More work is needed to further explore the optimal dose-including questions of frequency, intensity, time, and type - using longitudinal studies to disentangle temporality and to refine guidelines for the benefits of PA for academic achievement.

\section{Conclusion}

Overall, PA was positively associated with academic achievement among both elementary school and secondary school students prior to accounting for inattention and hyperactivity. Differences were 
observed between school levels; a dose-response pattern was observed for elementary school students with more PA days per week associated with greater academic benefit. In contrast, secondary school students required at least 3 to 4 days to see benefits, though no additional benefits to academic achievement were noted beyond 3 to 4 days. Furthermore, the benefits of PA on academic achievement may occur, in part, through reductions in inattention and hyperactivity, especially for secondary students. Though this research serves as an important first step to begin disentangling important issues, such as dose, school-level differences, and mechanisms underlying the relationship between PA and academic achievement, more work is needed to fully unpack this association.

\section{Notes}

${ }^{\text {I }}$ Confirmed significant differences between dummy coded PA variables by changing the reference category to make statistical comparisons between each option. See Supplementary Table 5 (available online).

${ }^{\mathrm{II}}$ Confirmed significant differences between dummy coded PA variables by changing the reference category to make statistical comparisons between each option. See Supplementary Table 6 (available online).

\section{Acknowledgments}

This research uses data from the 2014 SMHS (http://www. ontariochildhealthstudy.ca/smhs), a project led by Kathy Georgiades and Michael Boyle at McMaster University. The SMHS study was supported by the Canadian Institutes of Health Research (Funding Reference Number MOP-136939). Dr Georgiades holds the David R. (Dan) Offord Chair in Child studies. The authors declare that they have no competing interests.

\section{References}

1. Hills AP, Dengel DR, Lubans DR. Supporting public health priorities: recommendations for physical education and physical activity promotion in schools. Prog Cardiovasc Dis. 2015;57(4):368-374. PubMed ID: 25269062 doi:10.1016/j.pcad.2014.09.010

2. Wilkins J, Graham G, Parker S, Westfall S, Fraser R, Tembo M. Time in the arts and physical education and school achievement. J Curriculum Studies. 2003;35(6):721-734. doi:10.1080/002202703 2000035113

3. Sibley BA, Etnier JL. The relationship between physical activity and cognition in children: a meta-analysis. Ped Exerc Sci. 2003;15(3): 243-256. doi:10.1123/pes.15.3.243

4. Tomporowski PD, Davis CL, Miller PH, Naglieri JA. Exercise and children's intelligence, cognition, and academic achievement. Educ Psychol Rev. 2008;20(2):111-131. PubMed ID: 19777141 doi:10. 1007/s10648-007-9057-0

5. Ahamed Y, MacDonald H, Reed K, Naylor PJ, Liu-Ambrose T, Mckay H. School-based physical activity does not compromise children's academic performance. Med Sci Sports Exerc. 2007; 39(2):371-376.

6. Carlson SA, Fulton JE, Lee SM, et al. Physical education and academic achievement in elementary school: data from the early childhood longitudinal study. Am J Public Health. 2008;98(4):721727. PubMed ID: 18309127 doi:10.2105/AJPH.2007.117176

7. Castelli DM, Hillman CH, Buck SM, Erwin HE. Physical fitness and academic achievement in third- and fifth-grade students. J Sport Exerc Psychol. 2007;29(2):239-252. doi:10.1123/jsep.29.2.239
8. Donnelly JE, Hillman CH, Castelli D, et al. Physical activity, fitness, cognitive function, and academic achievement in children: a systematic review. Med Sci Sports Exerc. 2016;48(6):1197-1222. PubMed ID: 27182986 doi:10.1249/MSS.0000000000000901

9. Khan NA, Hillman $\mathrm{CH}$. The relation of childhood physical activity and aerobic fitness to brain function and cognition: a review. Pediatr Exerc Sci. 2014;26(2):138-146. PubMed ID: 24722921 doi:10.1123/ pes.2013-0125

10. Owen KB, Parker PD, Astell-Burt T, Lonsdale C. Regular physical activity and educational outcomes in youth: a longitudinal study. $J$ Adolesc Health. 2018;62(3):334-340. PubMed ID: 29229462 doi:10. 1016/j.jadohealth.2017.09.014

11. Singh A, Uijtdewilligen L, Twisk JW, Van Mechelen W, Chinapaw MJ. Physical activity and performance at school: a systematic review of the literature including a methodological quality assessment. Arch Pediatr Adolesc Med. 2012;166(1):49-55. PubMed ID: 22213750 doi:10.1001/archpediatrics.2011.716

12. Mahar MT, Murphy SK, Rowe DA, Golden J, Shields AT, Raedeke TD. Effects of a classroom-based program on physical activity and on-task behavior. Med Sci Sports Exerc. 2006;38(12):20862094. PubMed ID: 17146314 doi:10.1249/01.mss.0000235359. 16685.a3

13. Rasberry CN, Lee SM, Robin L, et al. The association between school-based physical activity, including physical education, and academic performance: a systematic review of the literature. Prev Med. 2011;52:S10-S20. PubMed ID: 21291905 doi:10.1016/j. ypmed.2011.01.027

14. Verburgh L, Königs M, Scherder EJ, Oosterlaan J. Physical exercise and executive functions in preadolescent children, adolescents and young adults: a meta-analysis. Br J Sports Med. 2014;48(12):973979. PubMed ID: 23467962 doi:10.1136/bjsports-2012-091441

15. Banich MT. Executive function: the search for an integrated account. Curr Dir Psychol Sci. 2009;18(2):89-94. doi:10.1111/j.1467-8721. 2009.01615.x

16. Best JR. Effects of physical activity on children's executive function: contributions of experimental research on aerobic exercise. Dev Rev. 2010;30(4):331-351. PubMed ID: 21818169 doi:10.1016/j.dr.2010. 08.001

17. Diamond A. Executive functions. Annu Rev Psychol. 2013;64(1): 135-168. PubMed ID: 23020641 doi:10.1146/annurev-psych-113011143750

18. Miyake A, Friedman NP, Emerson MJ, Witzki AH, Howerter A, Wager TD. The unity and diversity of executive functions and their contributions to complex "frontal lobe" tasks: a latent variable analysis. Cogn Psychol. 2000;41(1):49-100. PubMed ID: 10945922 doi:10. 1006/cogp.1999.0734

19. Booth JN, Tomporowski PD, Boyle JM, et al. Associations between executive attention and objectively measured physical activity in adolescence: findings from ALSPAC, a UK cohort. Ment Health Phys Act. 2013;6(3):212-219. doi:10.1016/j.mhpa.2013.09.002

20. Hillman CH, Buck SM, Themanson JR, Pontifex MB, Castelli DM. Aerobic fitness and cognitive development: event-related brain potential and task performance indices of executive control in preadolescent children. Dev Psychol. 2009;45(1):114-129. PubMed ID: 19209995 doi:10.1037/a0014437

21. Tremblay MS, Carson V, Chaput JP, et al. Canadian 24-hour movement guidelines for children and youth: an integration of physical activity, sedentary behaviour, and sleep. Appl Physiol Nutr Metab. 2016;41(6):S311-S327. doi:10.1139/apnm-2016-0151

22. Bengoechea EG, Sabiston CM, Ahmed R, Farnoush M. Exploring links to unorganized and organized physical activity during adolescence: the role of gender, socioeconomic status, weight status, and 
enjoyment of physical education. Res Q Exerc Sport. 2010;81(1): 7-16. doi:10.1080/02701367.2010.10599623

23. Coe DP, Peterson T, Blair C, Schutten MC, Peddie H. Physical fitness, academic achievement, and socioeconomic status in schoolaged youth. J Sch Health. 2013;83(7):500-507. PubMed ID: 23782093 doi:10.1111/josh.12058

24. Yousefi F, Mansor MB, Juhari RB, Redzuan MR, Talib MA. The relationship between gender, age, depression and academic achievement. Curr Res Psychol. 2010;6(1):61-66.

25. Hobin EP, Leatherdale ST, Manske S, Dubin JA, Elliott S, Veugelers $P$. A multilevel examination of gender differences in the association between features of the school environment and physical activity among a sample of grades 9 to 12 students in Ontario, Canada. BMC Public Health. 2012;12(1):74. doi:10.1186/1471-2458-12-74

26. Bélanger M, Gray-Donald K, O'Loughlin J, Paradis G, Hanley J. When adolescents drop the ball: sustainability of physical activity in youth. Am J Prev Med. 2009;37(1):41-49. PubMed ID: 19524143 doi:10.1016/j.amepre.2009.04.002

27. Fernandes M, de Sousa A, Medeiros AR, Del Rosso S, Stults-Kolehmainen M, Boullosa DA. The influence of exercise and physical fitness status on attention: a systematic review. Int Rev Sport Exerc Psychol. 2019;12(1):2021-234. doi:10.1080/1750984X.2018.1455889

28. de Greeff JW, Bosker RJ, Oosterlaan J, Visscher C, Hartman E. Effects of physical activity on executive functions, attention and academic performance in preadolescent children: a meta-analysis. J Sci Med Sport. 2018;21(5):501-507. doi:10.1016/j.jsams.2017.09.595

29. Best JR, Miller PH. A developmental perspective on executive function. Child Dev. 2010;81(6):1641-1660. PubMed ID: 21077853 doi:10.1111/j.1467-8624.2010.01499.x

30. Jurado MB, Rosselli M. The elusive nature of executive functions: a review of our current understanding. Neuropsychol Rev. 2007;17(3): 213-233. PubMed ID: 17786559 doi:10.1007/s11065-007-9040-z

31. Statistics Canada. Ontario child health study (OCHS). 2017. http:// www23.statcan.gc.ca/imdb/p2SV.pl?Function=getSurvey\&Id=185995.

32. Statistics Canada. The 2014 Ontario Child Health Study Adolescent Questionnaire (ages 14-17). 2014. https://ontariochildhealthstudy. s3.amazonaws.com/uploads/2014OCHS_Adolescent_14-17YRS_ July2014.pdf.

33. Duncan L, Georgiades K, Wang L, et al. The 2014 Ontario Child Health Study Emotional Behavioural Scales (OCHS-EBS) part I: a checklist for dimensional measurement of selected DSM-5 disorders. Can J Psychiatry. 2019;64(6):423-433. PubMed ID: 30376365 doi: $10.1177 / 0706743718808250$

34. Ottova-Jordan V, Smith OR, Augustine L, et al. Trends in health complaints from 2002 to 2010 in 34 countries and their association with health behaviours and social context factors at individual and macro-level. Eur J Public Health. 2015;25(suppl 2):83-89. doi:10. 1093/eurpub/ckv033

35. Enders CK, Keller BT, Levy R. A fully conditional specification approach to multilevel imputation of categorical and continuous variables. Psychol Methods. 2018;23(2):298-317. PubMed ID: 28557466 doi: $10.1037 /$ met0000148

36. Keller BT, Enders CK. Blimp user's guide version 1.1. http://www. appliedmissingdata.com/blimpuserguide-5.pdf.

37. SAS Institute Inc. SAS/STAT ${ }^{\circledR} 9.3$ User's Guide. Cary, NC: SAS Institute Inc.; 2011.

38. Yzerbyt V, Muller D, Batailler C, Judd CM. New recommendations for testing indirect effects in mediational models: the need to report and test component paths. J Pers Soc Psychol. 2018;115(6):929-943. PubMed ID: 30550319 doi:10.1037/pspa0000132
39. Hayes AF. Introduction to Mediation, Moderation, and Conditional Process Analysis: A Regression-Based Approach. New York, NY: Guilford Publications; 2017.

40. Selig JP, Preacher KJ. Monte Carlo method for assessing mediation: an interactive tool for creating confidence intervals for indirect effects [computer software]. 2008. http://quantpsy.org/.

41. MacKinnon DP, Lockwood CM, Hoffman JM, West SG, Sheets V. A comparison of methods to test mediation and other intervening variable effects. Psychol Methods. 2002;7(1):83. PubMed ID: 11928892 doi:10.1037/1082-989X.7.1.83

42. Bauer DJ, Preacher KJ, Gil KM. Conceptualizing and testing random indirect effects and moderated mediation in multilevel models: new procedures and recommendations. Psychol Methods. 2006;11(2): 142. PubMed ID: 16784335 doi:10.1037/1082-989X.11.2.142

43. Hayes AF, Rockwood NJ. Conditional process analysis: concepts, computation, and advances in the modeling of the contingencies of mechanisms. Am Behav Sci. 2020;64(1):19-54. doi:10.1177/ 0002764219859633

44. Pica R. Beyond physical development: why young children need to move. Young Child. 1997;52(6):4-11.

45. Leppo ML, Davis D, Crim B. The basics of exercising the mind and body. Child Educ. 2000;76(3):142-147. doi:10.1080/00094056. 2000.10522095

46. Darst PW, Pangrazi RP. Dynamic Physical Education for Secondary School Students. San Francisco, CA: Benjamin Cummings; 2002.

47. World Health Organization. Global Recommendations on Physical Activity for Health. Global Strategy on Diet, Physical Activity and Health. http://www.who.int/dietphysicalactivity/factsheet_ young people/en/

48. Salmon J, Owen N, Crawford D, Bauman A, Sallis JF. Physical activity and sedentary behavior: a population-based study of barriers, enjoyment, and preference. Health Psychol. 2003;22(2):178-188. PubMed ID: 12683738 doi:10.1037/0278-6133.22.2.178

49. Daly-Smith AJ, Zwolinsky S, McKenna J, Tomporowski PD, Defeyter MA, Manley A. Systematic review of acute physically active learning and classroom movement breaks on children's physical activity, cognition, academic performance and classroom behaviour: understanding critical design features. BMJ Open Sport Exerc Med. 2018;4(1):e000341. PubMed ID: 29629186 doi:10.1136/bmjsem2018-000341

50. Fenesi B, Lucibello K, Kim JA, Heisz JJ. Sweat so you don't forget: exercise breaks during a university lecture increase on-task attention and learning. J Appl Res Mem Cogn. 2018;7(2):261-269. doi:10. 1016/j.jarmac.2018.01.012

51. Watson A, Timperio A, Brown H, Best K, Hesketh KD. Effect of classroom-based physical activity interventions on academic and physical activity outcomes: a systematic review and meta-analysis. Int J Behav Nutr Phys Act. 2017;14(1):114. PubMed ID: 28841890 doi:10.1186/s12966-017-0569-9

52. Norris E, Shelton N, Dunsmuir S, Duke-Williams O, Stamatakis E. Physically active lessons as physical activity and educational interventions: a systematic review of methods and results. Prev Med. 2015;72:116-125. PubMed ID: 25562754 doi:10.1016/j.ypmed. 2014.12.027

53. Bedard C, St John L, Bremer E, Graham JD, Cairney J. A systematic review and meta-analysis on the effects of physically active classrooms on educational and enjoyment outcomes in school age children. PLoS One. 2019;14(6):e0218633. PubMed ID: 31237913 doi:10.1371/journal.pone.0218633 